\title{
Sachet Container
}

National Cancer Institute

\section{Source}

National Cancer Institute. Sachet Container. NCI Thesaurus. Code C149889.

Container consisting of two surfaces made of flexible material to be closed only by sealing or folding over. The contents are intended for single use. 